Article

\title{
Design and Implementation of the Battery Energy Storage System in DC Micro-Grid Systems
}

\author{
Yuan-Chih Chang *, Hao-Chin Chang and Chien-Yu Huang \\ Department of Electrical Engineering and Advanced Institute of Manufacturing with High-Tech Innovations, \\ National Chung Cheng University, Chiayi 62102, Taiwan; aloner330@gmail.com (H.-C.C.); \\ apr3693@gmail.com (C.-Y.H.) \\ * Correspondence: ycchang@ccu.edu.tw; Tel.: +886-5-272-9108
}

Received: 25 May 2018; Accepted: 12 June 2018; Published: 14 June 2018

\begin{abstract}
The design and implementation of the battery energy storage system in DC micro-grid systems is demonstrated in this paper. The battery energy storage system (BESS) is an important part of a DC micro-grid because renewable energy generation sources are fluctuating. The BESS can provide energy while the renewable energy is absent in the DC micro-grid. The circuit topology of the proposed BESS will be introduced. The design of the voltage controller and the current controller for the battery charger/discharger are also illustrated. Finally, experimental results are provided to validate the performance of the BESS.
\end{abstract}

Keywords: battery energy storage system; DC micro-grid; voltage control; current control

\section{Introduction}

Reducing carbon emissions and mitigating the global warming are the main advantages of using renewable energy [1-3]. However, renewable energy fluctuates with its environmental parameters. Therefore, an AC microgrid [4-6] and a DC microgrid [7-9] are implemented to treat this issue. Renewable energy in a microgrid can be solar or wind power. Extra electricity can be stored in an energy storage system [10-13]. If the renewable energy sources are absent, the micro-grid will be stabilized via the energy storage system. In this paper, the battery energy storage system (BESS) is designed and implemented in a DC micro-grid.

Takagi-Sugeno Fuzzy [14], proposed by Takagi and Sugeno, is a control system based on fuzzy-logic. In T-S Fuzzy systems, a nonlinear system can be resembled by linear sub-systems. The controllers of the T-S Fuzzy system are designed on the concept of parallel-distributed compensation (PDC) [15]. Lyapunov theorem [16] can be applied to prove the stability of a T-S Fuzzy control system. The stability specifications are displayed in the form of linear matrix inequality (LMI). The T-S Fuzzy control applied to the DC-DC converter can be classified as buck [17] and boost [18] converters. Nevertheless, the non-ideal characteristics of the circuit elements are not treated in the literature. The non-ideal circuit elements are treated in this research to increase control precision and performance.

A battery energy storage system in DC micro-grid systems is designed and implemented. A BESS consists of the battery and the charger/discharger. A buck converter, combined with a boost converter, is implemented as the charger/discharger. If the battery needs to be charged, the buck converter is operated as a charger. Furthermore, the boost converter is operated as a discharger to release electric energy. In this paper, the BESS in the DC micro-grid system is first illustrated. Next, the circuit topology, considering non-ideal circuit models, is demonstrated. After that, the state equations of the BESS are obtained through the state-space average scheme. Then, the voltage and current controllers of the BESS are designed via T-S Fuzzy controls. The system stability of the BESS is proved and 
verified. The control performances of the voltage controller and current controller are validated by experimental results.

\section{System Configuration}

The system configuration of the DC micro-grid is shown in Figure 1. The developed battery energy storage system consists of the battery and the bidirectional DC/DC converter. Figure 2 shows the circuit configuration of the battery charger/discharger. The buck converter and boost converter is combined to form the bidirectional converter. In charging mode, the buck converter is operated with $\left(M_{1}, D_{2}\right)$, while in discharging mode, the boost converter is operated with $\left(M_{2}, D_{1}\right)$. The non-ideal circuit elements are included in the circuit configuration. The non-ideal elements include the equivalent series resistance (ESR) of the power switch $\left(R_{M}\right)$, the ESR of the inductor $\left(R_{L}\right)$, the ESR of the capacitor $\left(R_{C_{B}}, R_{C_{D C}}\right)$, and the forward conduction voltage of the diode $\left(V_{D}\right)$. Inductance current $i_{L}$, DC-link voltage $V_{D C}$ and battery voltage $V_{B}$ are used to determine the duty ratio of the power switches. The feedback signals are sampled by the analog-to-digital converter (ADC). The control of the bidirectional DC/DC converter is digitally realized via the microcontroller Renesas RX62T.

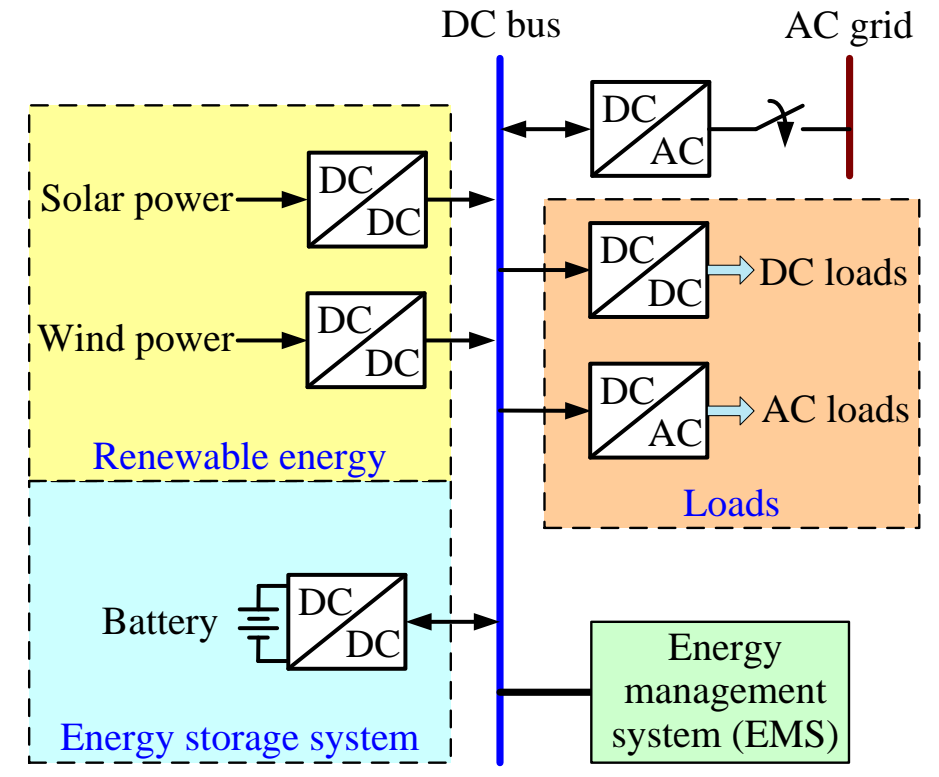

Figure 1. System configuration of the DC micro-grid.

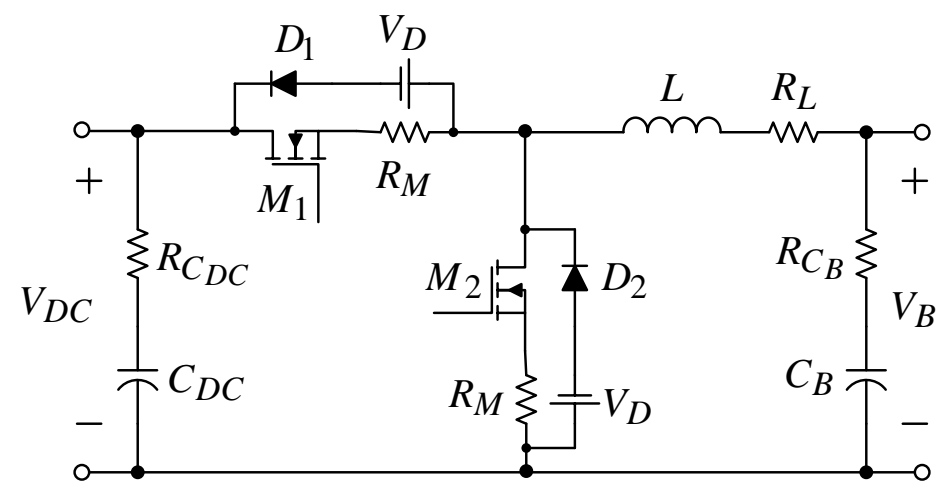

Figure 2. Circuit configuration of the battery charger/discharger. 


\section{Operation Modes and State Equations}

\subsection{Charging Mode}

At charging mode, the power switch $M_{2}$ is kept off. The duty ratio of the power switch $M_{1}$ is controlled to regulate the inductance current. When $M_{1}$ is turned on, the inductance will be magnetized and the inductance current rises. When $M_{1}$ is turned off, the diode $D_{2}$ will be forced to turn on. Then the inductance is de-magnetized and the inductance current will fall.

The state space average scheme can be used to find the state equations of charging mode:

$$
\left[\begin{array}{c}
i_{L} \\
\dot{V}_{C_{B}}
\end{array}\right]=\left[\begin{array}{cc}
-\frac{1}{L}\left(R_{L}+\frac{R R_{C_{B}}}{R+R_{C_{B}}}\right) & -\frac{R}{L\left(R+R_{C_{B}}\right)} \\
\frac{R}{C_{B}\left(R+R_{C_{B}}\right)} & -\frac{1}{C_{B}\left(R+R_{C_{B}}\right)}
\end{array}\right]\left[\begin{array}{c}
i_{L} \\
V_{C_{B}}
\end{array}\right]+\left[\begin{array}{c}
\frac{1}{L}\left(V_{D C}+V_{D}-i_{L} R_{M}\right) \\
0
\end{array}\right] D+\left[\begin{array}{c}
-\frac{V_{D}}{L} \\
0
\end{array}\right]
$$

where $R$ is the load resistance and $D$ is the duty ratio of $M_{1}$. The output is the inductance current:

$$
y=i_{L}=\left[\begin{array}{ll}
1 & 0
\end{array}\right]\left[\begin{array}{c}
i_{L} \\
V_{C_{B}}
\end{array}\right]
$$

\subsection{Discharging Mode}

At discharging mode, the power switch $M_{1}$ is kept off. The duty ratio of the power switch $M_{2}$ is controlled to regulate the output voltage. When $M_{2}$ is turned on, the inductance current rises. When $M_{2}$ is turned off, the diode $D_{1}$ will be forced to turn on. Then, the inductance current falls.

The state space average scheme is also used to find the state equations of discharging mode:

$$
\begin{gathered}
{\left[\begin{array}{c}
\dot{i}_{L} \\
\dot{V}_{C_{D C}}
\end{array}\right]=\left[\begin{array}{cc}
-\frac{1}{L}\left(R_{L}+\frac{R R_{C_{D C}}}{R+R_{C_{D C}}}\right) & -\frac{R}{L\left(R+R_{C_{D C}}\right)} \\
\frac{R}{C_{D C}\left(R+R_{C_{D C}}\right)} & -\frac{1}{C_{D C}\left(R+R_{C_{D C}}\right)}
\end{array}\right]\left[\begin{array}{c}
i_{L} \\
V_{C_{D C}}
\end{array}\right]} \\
+\left[\begin{array}{c}
\frac{1}{L}\left[V_{D}+\left(\frac{R R_{C_{D C}}}{R+R_{C_{D C}}}-R_{M}\right) i_{L}+\frac{R}{R+R_{C_{D C}}} V_{C_{D C}}\right] \\
-\frac{1}{C_{D C}\left(R+R_{C_{D C}}\right)} i_{L}
\end{array}\right] D+\left[\begin{array}{c}
\frac{V_{B}-V_{D}}{L} \\
0
\end{array}\right]
\end{gathered}
$$

where $D$ is the duty ratio of $M_{1}$. The output is the DC-link voltage:

$$
y=V_{D C}=\left[\begin{array}{cc}
\frac{R R_{C_{D C}}}{R+R_{C_{D C}}} & \frac{R}{R+R_{C_{D C}}}
\end{array}\right]\left[\begin{array}{c}
i_{L} \\
V_{C_{D C}}
\end{array}\right]-\frac{R R_{C_{D C}}}{R+R_{C_{D C}}} i_{L} D
$$

\section{Design of Current Controller and Voltage Controller}

In charging/discharging mode, the current/voltage tracking error will converge to zero by defining a new state variable:

$$
x_{e r r}(t)=\int(r-y(t)) d t
$$

where $r$ is desired value of inductance current for charger and output voltage for discharger.

By combining Equations (1), (2) and (5), the expanded state equations of the charger can be obtained as:

$$
\left[\begin{array}{c}
\dot{i}_{L} \\
\dot{V}_{C_{B}} \\
\dot{x}_{\text {err }}
\end{array}\right]=\left[\begin{array}{ccc}
-\frac{1}{L}\left(R_{L}+\frac{R R_{C_{B}}}{R+R_{C_{B}}}\right) & -\frac{R}{L\left(R+R_{C_{B}}\right)} & 0 \\
\frac{R}{C_{B}\left(R+R_{C_{B}}\right)} & -\frac{1}{C_{B}\left(R+R_{C_{B}}\right)} & 0 \\
-\frac{R R_{C_{B}}}{R+R_{C_{B}}} & -\frac{R}{R+R_{C_{B}}} & 0
\end{array}\right]\left[\begin{array}{c}
i_{L} \\
V_{C_{B}} \\
x_{\text {err }}
\end{array}\right]+\left[\begin{array}{c}
\frac{1}{L}\left(V_{D C}+V_{D}-i_{L} R_{M}\right) \\
0 \\
0
\end{array}\right] D+\left[\begin{array}{c}
-\frac{V_{D}}{L} \\
0 \\
r
\end{array}\right]
$$




$$
y=\left[\begin{array}{lll}
1 & 0 & 0
\end{array}\right]\left[\begin{array}{c}
i_{L} \\
V_{C_{B}} \\
x_{e r r}
\end{array}\right]
$$

Furthermore, by combining Equations (3)-(5), the expanded state equations of the discharger can be obtained as:

$$
\begin{aligned}
& {\left[\begin{array}{c}
\dot{i}_{L} \\
\dot{V}_{C_{D C}} \\
\dot{x}_{e r r}
\end{array}\right]=\left[\begin{array}{ccc}
-\frac{1}{L}\left(R_{L}+\frac{R R_{C_{D C}}}{R+R_{C_{D C}}}\right) & -\frac{R}{L\left(R+R_{C_{D C}}\right)} & 0 \\
\frac{R}{C_{D C}\left(R+R_{C_{D C}}\right)} & -\frac{1}{C_{D C}\left(R+R_{C_{D C}}\right)} & 0 \\
-\frac{R R_{C_{D C}}}{R+R_{C_{D C}}} & -\frac{R}{R+R_{C_{D C}}} & 0
\end{array}\right]\left[\begin{array}{c}
i_{L} \\
V_{C_{D C}} \\
x_{\text {err }}
\end{array}\right]} \\
& +\left[\begin{array}{c}
\frac{1}{L}\left[V_{D}+\left(\frac{R R_{C_{D C}}}{R+R_{C_{D C}}}-R_{M}\right) i_{L}+\frac{R}{R+R_{C_{D C}}} V_{C_{D C}}\right] \\
-\frac{1}{C_{D C}\left(R+R_{C_{D C}}\right)} i_{L} \\
\frac{R R_{C_{D C}}}{R+R_{C_{D C}}} i_{L}
\end{array}\right] D+\left[\begin{array}{c}
\frac{V_{B}-V_{D}}{L} \\
0 \\
r
\end{array}\right] \\
& y=V_{D C}=\left[\begin{array}{lll}
\frac{R R_{C_{D C}}}{R+R_{C_{D C}}} & \frac{R}{R+R_{C_{D C}}} & 0
\end{array}\right]\left[\begin{array}{c}
i_{L} \\
V_{C_{D C}} \\
x_{\text {err }}
\end{array}\right]-\frac{R R_{C_{D C}}}{R+R_{C_{D C}}} i_{L} D
\end{aligned}
$$

For convenience, Equations (6) and (8) are represented in general state-equation form:

$$
\dot{x}(t)=A x(t)+B u(t)+E v(t)
$$

where $v(t)$ are the disturbances of the system.

In the T-S fuzzy models, the nonlinear BESS are represented by linear sub-systems according to the model rules:

Model rules $i$ : If $z_{1}(t)$ is $M_{i 1}$ and $\ldots$ and $z_{\mathrm{p}}(t)$ is $M_{\mathrm{ip}}$, then

$$
\dot{x}(t)=A_{i} x(t)+B_{i} u(t)
$$

where $u(t)$ are the control inputs, $x(t)$ are the state variables, $A_{i}, B_{i}$ are the state matrices of the sub-systems, $M_{\mathrm{ip}}$ is the fuzzy set. In charging mode, $i_{L}$ is chosen as $z_{\mathrm{p}}(t)$. In discharging mode, $i_{L}$, $V_{C D C}$ are chosen as $z_{\mathrm{p}}(t)$. The T-S fuzzy system of the BESS can be expressed after defuzzification:

$$
\dot{x}(t)=\sum_{i=1}^{r} h_{i}(z(t))\left\{A_{i} x(t)+B_{i} u(t)\right\}
$$

where:

$$
h_{i}(z(t))=\frac{\prod_{j=1}^{r} M_{i j}\left(z_{j}(t)\right)}{\sum_{i=1}^{r} \prod_{j=1}^{r} M_{i j}\left(z_{j}(t)\right)}
$$

and $M_{i j}\left(z_{j}(t)\right)$ is the grad of membership.

The PDC controllers of the BESS are expressed as:

Control rules $i$ : If $Z_{1}(t)$ is $M_{i 1}$ and $\ldots$ and $z_{\mathrm{p}}(t)$ is $M_{\mathrm{ip}}$, then

$$
u(t)=-\sum_{i=1}^{r} h_{i}(z(t)) F_{i} x(t)
$$

By substituting (14) into (12), the close-loop system are obtained:

$$
\dot{x}(t)=\sum_{i=1}^{r} \sum_{j=1}^{r} h_{i}(z(t)) h_{j}(z(t))\left\{A_{i}-B_{i} F_{j}\right\} x(t)
$$


According to state Equation (10), the BESS T-S fuzzy system with disturbances is found:

$$
\begin{gathered}
\dot{x}(t)=\sum_{i=1}^{r} h_{i}(z(t))\left\{A_{i} x(t)+B_{i} u(t)+E_{i} v(t)\right\} \\
y(t)=\sum_{i=1}^{r} h_{i}(z(t)) C_{i} x(t)
\end{gathered}
$$

To suppress the disturbances, the $H_{\infty}$ performance index is defined:

$$
\sup _{\|v(t)\|_{2} \neq 0} \frac{\|y(t)\|_{2}}{\|v(t)\|_{2}} \leq \gamma, \quad 0 \leq \gamma \leq 1
$$

where $\gamma$ is the disturbance suppression ability index.

To analyze the stability of the designed current and voltage controller, Lyapunov theorem [19] is applied to find the following LMI condition:

$$
\left[\begin{array}{ccc}
X A_{i}^{T}-M_{j}^{T} B_{i}^{T}+A_{i} X-B_{i} M_{j} & E_{i} & -X C_{i}^{T} \\
E_{i}^{T} & -\gamma^{2} I & 0 \\
-C_{j} X & 0 & -I
\end{array}\right]<0, i \leq j
$$

where $X$ is a positive definite matrix and $X=P^{-1}, M_{j}=F_{j} X$.

\section{Results and Discussions}

Table 1 lists the specifications of the BESS.

For buck mode, the $H_{\infty}$ performance index is selected as $\gamma=0.7$. For boost mode, the $H_{\infty}$ performance index is selected as $\gamma=0.8$. The controller gains $F_{i}$ are obtained by using the LMI toolbox in MATLAB.

Table 1. Specifications of the BESS.

\begin{tabular}{cccc}
\hline Rated power & $2 \mathrm{~kW}$ & $V_{D}$ & $1.5 \mathrm{~V}$ \\
Inductance & $1.97 \mathrm{mH}$ & $R_{M}$ & $0.079 \mathrm{U}$ \\
Input voltage & $380 \mathrm{~V}(\mathrm{DC})$ & Input capacitance & $560 \mu \mathrm{F}$ \\
Output voltage & $100 \mathrm{~V}(\mathrm{DC})$ & Output capacitance & $440 \mu \mathrm{F}$ \\
\hline
\end{tabular}

\subsection{Charging Mode}

The load resistance is constant and the input voltage $V_{D C}$ is $380 \mathrm{~V}$. The current commands are $5 \mathrm{~A}$ and $20 \mathrm{~A}$. The inductance current and battery voltage at current command $5 \mathrm{~A}$, load $=20 \mathrm{U}(500 \mathrm{~W})$, and current command $20 \mathrm{~A}$, load $=5 \mathrm{U}(2 \mathrm{~kW})$ are shown in Figure 3a,b, respectively. It can be found that the inductance current can accurately track the command.

Next, the load is constant (10 $\grave{\mathrm{U}})$ and the input voltage $V_{D C}$ is also $380 \mathrm{~V}$. The current command is variable $5 \mathrm{~A} \rightarrow 10 \mathrm{~A} \rightarrow 5 \mathrm{~A}$. Figure 4 shows the inductance current and battery voltage with current command variation. It is clear that the inductance current tracks the command accurately. 


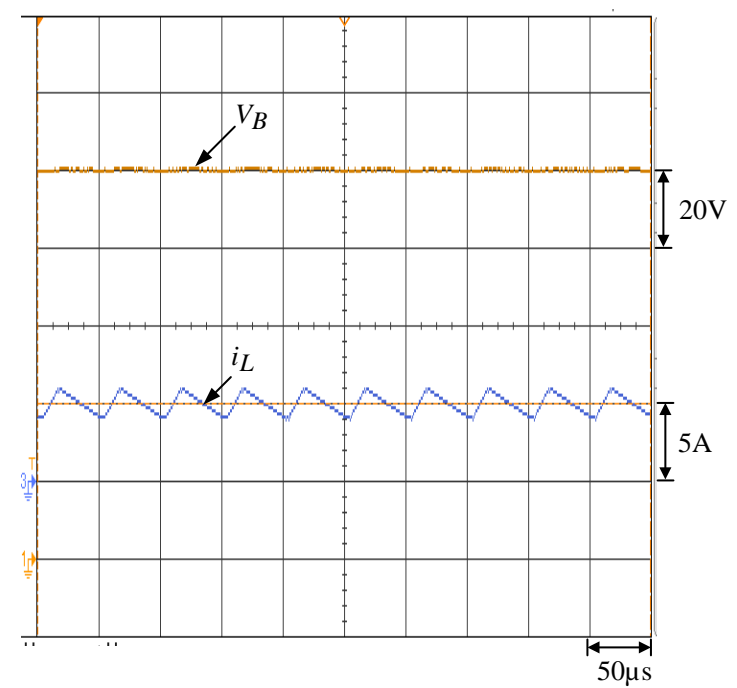

(a)

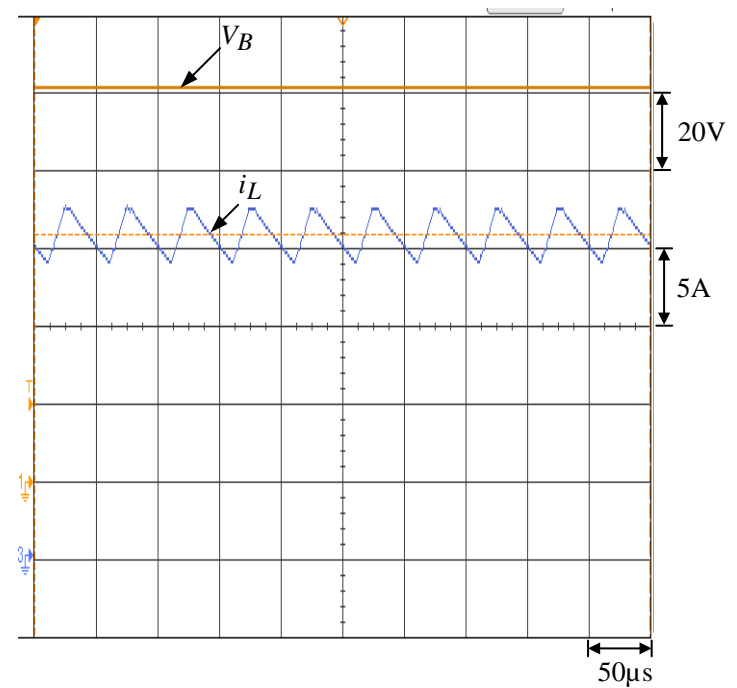

(b)

Figure 3. Inductance current and battery voltage at constant load resistance: (a) current command $5 \mathrm{~A}$, 20 Ù (500 W); (b) current command 20 A, 5 Ù (2 kW).

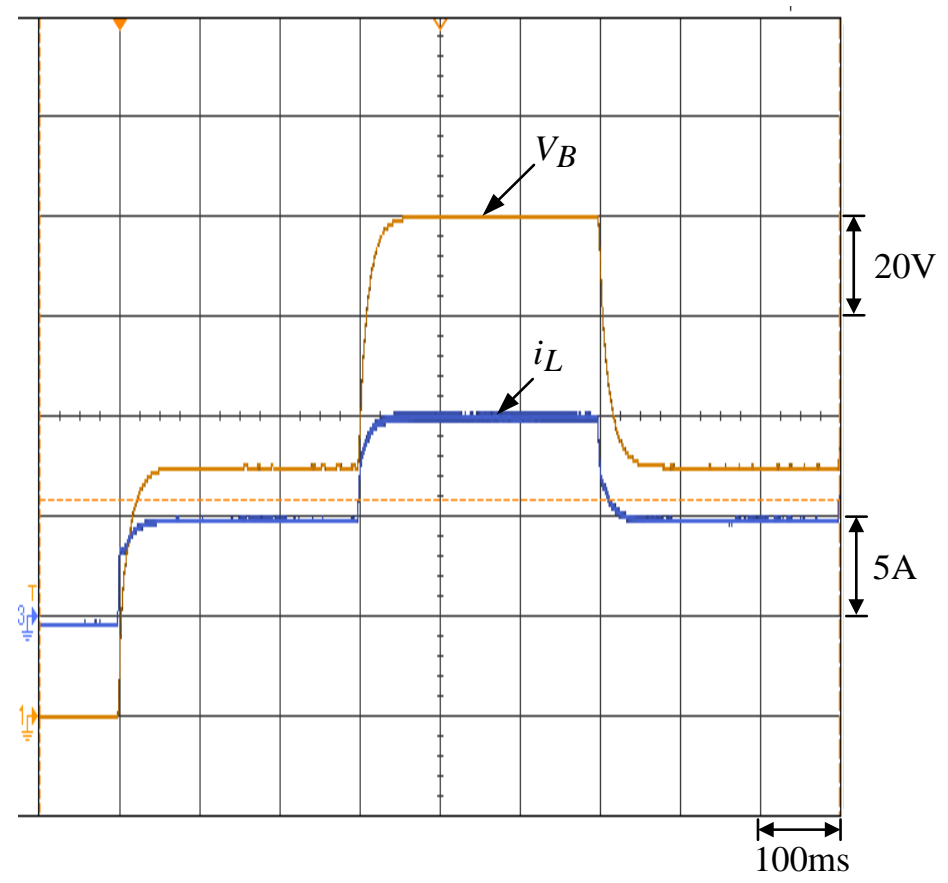

Figure 4. Inductance current and battery voltage with current command variation $5 \mathrm{~A} \rightarrow 10 \mathrm{~A} \rightarrow 5 \mathrm{~A}$ (load 10 Ù).

\subsection{Discharging Mode}

The load resistance is constant and the input battery voltage $V_{B}$ is $100 \mathrm{~V}$. Figure $5 \mathrm{a}, \mathrm{b}$ shows the inductance current and DC-link voltage at load $=250 \mathrm{U}(577.6 \mathrm{~W})$ and $135.7 \mathrm{U}(1.06 \mathrm{~kW})$, respectively. It is obvious that the DC-link voltage can exactly track the command $380 \mathrm{~V}$.

Next, the input voltage $V_{B}$ is $100 \mathrm{~V}$, and the load is variable $250 \grave{\mathrm{U}} \rightarrow 135.7 \mathrm{U} \rightarrow 250 \mathrm{U}$. Figure $6 \mathrm{a}, \mathrm{b}$ shows the inductance current and DC-link voltage under load variation $300 \mathrm{U} \rightarrow 150 \mathrm{U}$ and $150 \mathrm{U} \rightarrow$ $300 \mathrm{U}$. It can be seen that the DC-link voltage is well regulated under load variation. 


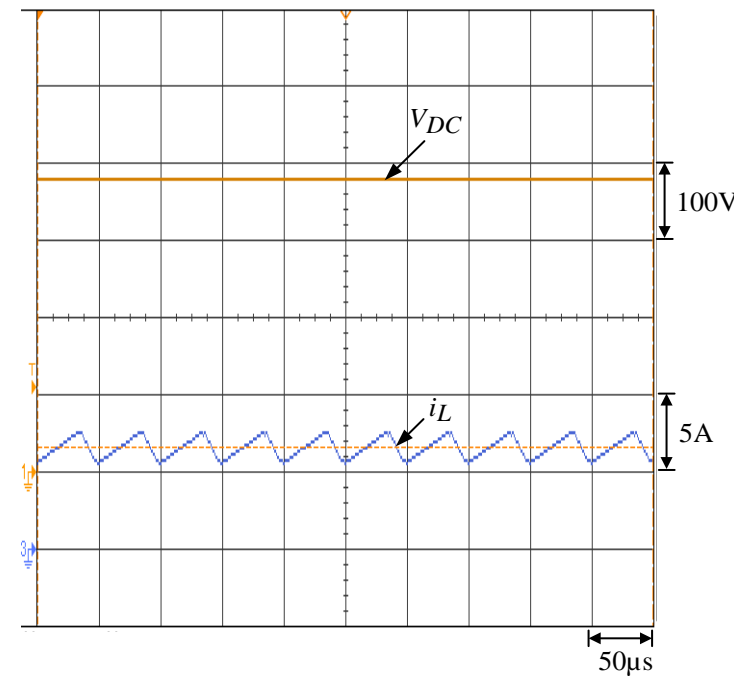

(a)

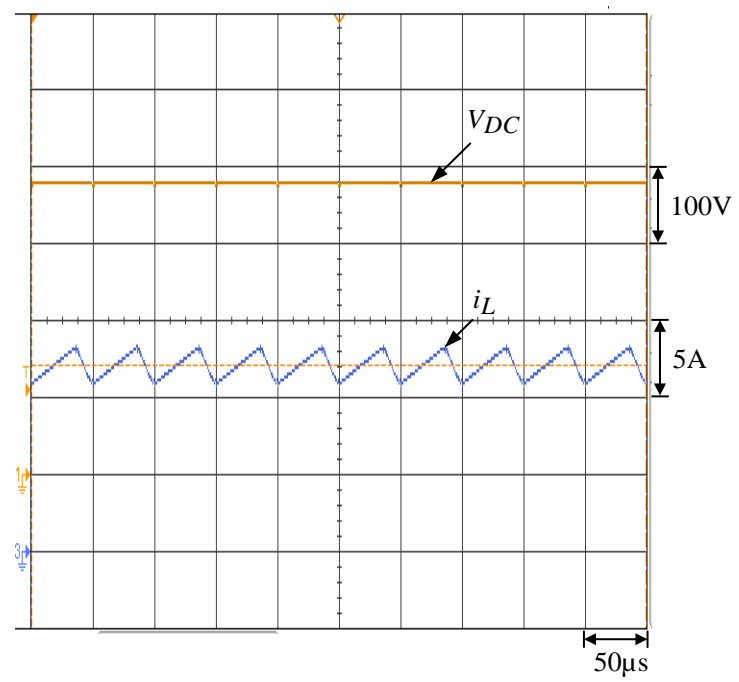

(b)

Figure 5. Inductance current and DC-link voltage at constant load: (a) 250 Ù (577.6 W); (b) 135.7 Ù $(1.06 \mathrm{~kW})$.

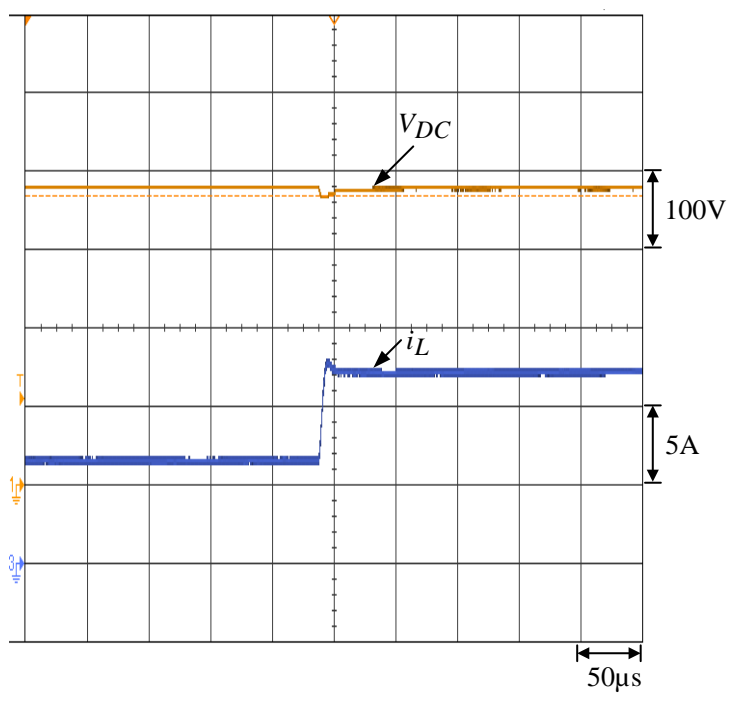

(a)

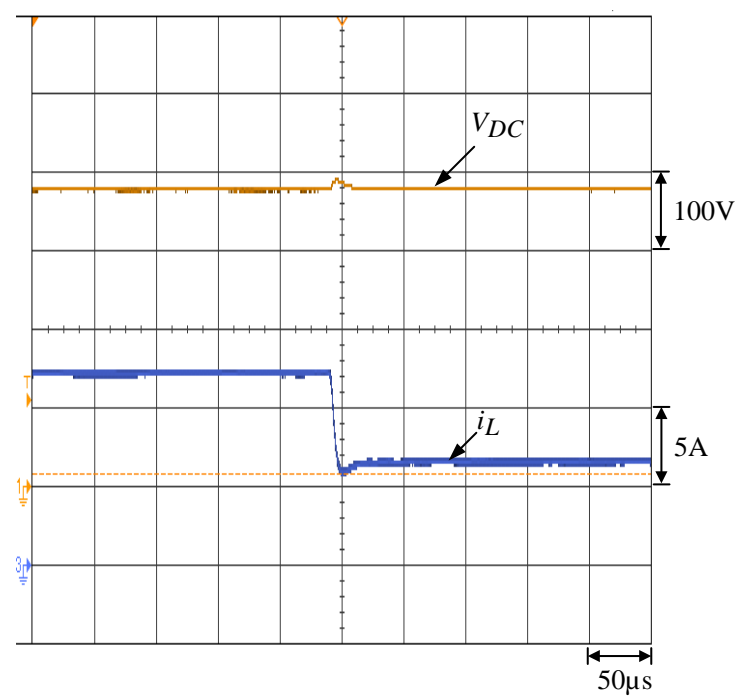

(b)

Figure 6. Inductance current and DC-link voltage under load variation: (a) 250 Ù $\rightarrow 135.7$ U்; (b) 135.7 Ù $\rightarrow 250$ Ù.

\section{Conclusions}

A battery energy storage system in DC micro-grid systems is designed and implemented. T-S Fuzzy current control and voltage control of the BESS is introduced. The system stability with disturbance suppression ability is analyzed and shown. The performance of the current controller and voltage controller is verified via experimental results.

Author Contributions: The authors contributed equally to this work.

Funding: This research was supported by the Ministry of Science and Technology, Taiwan, under the Grant of MOST 106-2221-E-194-037.

Conflicts of Interest: The authors declare no conflict of interest. 


\section{References}

1. Carrizosa, M.J.; Arzandé, A.; Navas, F.D.; Damm, G.; Vannier, J.-C. A control strategy for multiterminal DC grids with renewable production and storage devices. IEEE Trans. Sustain. Energy 2018, 9, 930-939. [CrossRef]

2. Dahmani, O.; Bourguet, S.; Machmoum, M.; Guerin, P.; Rhein, P.; Josse, L. Optimization and reliability evaluation of an offshore wind farm architecture. IEEE Trans. Sustain. Energy 2017, 8, 542-550. [CrossRef]

3. Sharma, S.K.; Chandra, A.; Saad, M.; Lefebvre, S.; Asber, D.; Lenoir, L. Voltage flicker mitigation smart loads with high penetration of renewable energy in distribution systems. IEEE Trans. Sustain. Energy 2017, 8, 414-424. [CrossRef]

4. Sahoo, S.K.; Sinha, A.K.; Kishore, N.K. Control techniques in AC, DC, and hybrid AC-DC microgrid: A review. IEEE J. Emerg. Sel. Top. Power Electron. 2018, 6, 738-759. [CrossRef]

5. Kim, J.; Guerrero, J.M.; Rodriguez, P.; Teodorescu, R.; Nam, K. Mode adaptive droop control with virtual output impedances for an inverter-based flexible AC microgrid. IEEE Trans. Power Electron. 2011, 26, 689-701. [CrossRef]

6. Han, R.; Meng, L.; Ferrari-Trecate, G.; Coelho, E.A.A.; Vasquez, J.C.; Guerrero, J.M. Containment and consensus-based distributed coordination control to achieve bounded voltage and precise reactive power sharing in islanded AC microgrids. IEEE Trans. Ind. Appl. 2017, 53, 5187-5199. [CrossRef]

7. Wang, M.-H.; Mok, K.-T.; Tan, S.-C.; Hui, S.Y. Multifunctional DC electric springs for improving voltage quality of DC grids. IEEE Trans. Smart Grid 2018, 9, 2248-2258. [CrossRef]

8. Kumar, M.; Srivastava, S.C.; Singh, S.N. Control strategies of a DC microgrid for grid connected and islanded operations. IEEE Trans. Smart Grid 2015, 6, 1558-1601. [CrossRef]

9. Radwan, A.A.A.; Mohamed, Y.A.-R.I. Linear active stabilization of converter-dominated DC microgrids. IEEE Trans. Smart Grid 2012, 3, 203-216. [CrossRef]

10. Abeywardana, D.B.W.; Hredzak, B.; Agelidis, V.G. A fixed-frequency sliding mode controller for a boost-inverter-based battery-supercapacitor hybrid energy storage system. IEEE Trans. Power Electron. 2017, 32, 668-680. [CrossRef]

11. Ciccarelli, F.; Iannuzzi, D.; Kondo, K.; Fratelli, L. Line-voltage control based on wayside energy storage systems for tramway networks. IEEE Trans. Power Electron. 2016, 31, 884-899. [CrossRef]

12. Akter, M.P.; Mekhilef, S.; Tan, N.M.L.; Akagi, H. Modified model predictive control of a bidirectional AC-DC converter based on Lyapunov function for energy storage systems. IEEE Trans. Ind. Electron. 2016, 63, 704-715. [CrossRef]

13. Cacciato, M.; Nobile, G.; Scarcella, G.; Scelba, G. Real-time model-based estimation of SOC and SOH for energy storage systems. IEEE Trans. Power Electron. 2017, 32, 794-803. [CrossRef]

14. Takagi, T.; Sugeno, M. Fuzzy identification of systems and its applications to modeling and control. IEEE Trans. Syst. Man Cybern. 1985, SMC-1, 116-132. [CrossRef]

15. Lam, H.K.; Leung, F.H.F. LMI-based stability and performance conditions for continuous-time nonlinear systems in Takagi-Sugeno's form. IEEE Trans. TSMCB 2007, 37, 1396-1406. [CrossRef]

16. Tanaka, K.; Sugeno, M. Stability analysis and design of fuzzy control systems. Fuzzy Sets Syst. 1992, 45, 135-156. [CrossRef]

17. Lian, K.Y.; Liou, J.J.; Huang, C.Y. LMI-based integral fuzzy control of DC-DC converters. IEEE Trans. Fuzzy Syst. 2006, 14, 71-80. [CrossRef]

18. Mehran, K.; Giaouris, D.; Zahawi, B. Stability analysis and control of nonlinear phenomena in boost converters using model-based Takagi-Sugeno fuzzy approach. IEEE Trans. Circuits Syst. I Reg. Pap. 2010, 57, 200-212. [CrossRef]

19. Chang, Y.C.; Chen, C.H.; Zhu, Z.C.; Huang, Y.W. Speed control of the surface-mounted permanent-magnet synchronous motor based on Takagi-Sugeno fuzzy models. IEEE Trans. Power Electron. 2016, 31, 6504-6510. [CrossRef]

(C) 2018 by the authors. Licensee MDPI, Basel, Switzerland. This article is an open access article distributed under the terms and conditions of the Creative Commons Attribution (CC BY) license (http://creativecommons.org/licenses/by/4.0/). 